\title{
THE SURVIVAL OF INTRAUTERINE SKIN AUTOGRAFTS AND ALLOGRAFTS IN SHEEP
}

\author{
T. J. REIMERS AND P. J. DZIUK \\ Department of Animal Science-Genetics, University of Illinois, \\ Urbana, Illinois 61801, U.S.A.
}

(Received 20th September 1973)

\begin{abstract}
Summary. Autografts and allografts of skin were transplanted into the uteri of ewes to determine the influence of ovariectomy and hormone replacement on survival of the grafts. The fate of the grafts in sheep differed from that previously reported for the rat. Autografts were accepted in the uteri of ovariectomized ewes. Intrauterine allografts were rejected, however, when oestrogen and progesterone were given to the hosts in doses sufficient to maintain pregnancy.
\end{abstract}

The mammalian embryo in the uterus is a genetically alien tissue graft that occurs naturally and is accepted immunologically by the host. Several studies have been undertaken to explain this invulnerability of the embryo by examination of the conditions necessary for successful intrauterine survival of nonembryonic tissue and cellular grafts (Poppa, Simmons, David \& Russell, 1964; Zipper, Ferrando, Saez \& Tchernitchin, 1966; Watnick \& Russo, 1968; McLean \& Scothorne, 1968; Beer \& Billingham, 1970).

It was the purpose of this study to determine the influence of ovariectomy and hormone replacement on survival of intrauterine autografts and allografts in sheep.

Autografts and allografts of skin were transplanted in apposition to the endometrium of fifteen 2-year-old Columbian ewes of three endocrine states. Group 1 consisted of four ewes that received grafts during the anoestrous season when the ovaries were relatively inactive. The five anoestrous ewes of Group II were bilaterally ovariectomized on the day of grafting further to reduce the source of oestrogen and progesterone. The six ewes of Group III were also anoestrous but received chronic implants of polysiloxane impregnated with progesterone 3 days before grafting. Each implant released about $3 \mathrm{mg}$ progesterone per day. This was followed 1 day before grafting with a subcutaneous injection of $50 \mu \mathrm{g}$ oestradiol-17 $\beta$ in corn oil.

Ewes were anaesthetized with an intravenous injection of $17 \mathrm{ml}$ pentobarbital sodium solution $(65 \mathrm{mg} / \mathrm{ml})$. The abdomen was shorn of wool, shaved and disinfected with a $70 \%$ solution of ethyl alcohol. Strips of skin, $4 \mathrm{~cm} \times 0.5 \mathrm{~cm}$ each, were removed from the ventral mid-line of donor Columbian ewes and placed in Petri dishes containing sterile saline. The uteri of the recipient ewes 
were exposed and the technique of Watnick \& Russo (1968) was used for insertion of the grafts. Two small puncture wounds about $3 \mathrm{~cm}$ apart were made in each uterine horn with a scalpel handle. A barbed 3 in. 20-gauge needle was inserted through the two incisions of a uterine horn, the graft was hooked to the barb and the needle withdrawn bringing the graft into the lumen of the uterus. Both ends of the graft were left protruding from the uterus and were anchored to the outside of the uterus with metal wound clips. In each ewe, an allograft was transplanted to the left and an autograft to the right uterine horn.

The ewes were killed 21 days after grafting and the uteri were opened and examined. If a graft was rejected, it was no longer present in the uterine horn at the time of autopsy (Pl. 1, Fig. 1). If a graft was accepted, it was intact with a new dense growth of wool and was firmly attached along its entire length to the endometrium (Pl. 1, Fig. 1).

The grafts and adjacent uterine tissue were fixed in neutral formalin and sections were stained with haematoxylin and eosin for histological examination. The abundance of dermal papillae, hair follicles and glandular structures was evidence that the grafts had been accepted and were viable (Pl. 1, Fig. 2).

The fates of the grafts are shown in Table 1. All allografts were rejected by 21 days after transplantation into the uterus, whereas fourteen of fifteen autografts

Table 1. Fate of intrauterine skin grafts in sheep 21 days after grafting

\begin{tabular}{c|cc}
\hline \multicolumn{1}{c|}{ Treatment group } & \multicolumn{2}{|c}{ No. of grafts accepted/total no. of grafts } \\
\cline { 2 - 3 } & Autografts & Allografts \\
\hline I. Anoestrous & $3 / 4$ & $0 / 4$ \\
II. Ovariectomized & $5 / 5$ & $0 / 5$ \\
III. Anoestrous + oestradiol and progesterone* & $6 / 6$ & $0 / 6$ \\
\hline
\end{tabular}

\footnotetext{
* Day 0 , grafting performed; Day 1, $50 \mu \mathrm{g}$ oestradiol injected intramuscularly; Day 3,
} progesterone-impregnated implant inserted.

in ewes of the three groups were accepted. The one autograft that was regarded as rejected was severed into two pieces and may have been inadvertently cut when the uterine horn was opened for examination; it otherwise appeared healthy.

The ends of the autografts and allografts protruding through the uterus into the abdominal cavity were intact.

Zipper et al. (1966) and Beer \& Billingham (1970) found that genetically compatible intrauterine skin grafts were not accepted in ovariectomized rats unless exogenous oestrogen was administered (Beer \& Billingham, 1970). Autografts did survive in the uteri of anoestrous and ovariectomized ewes. An endogenous or exogenous source of oestrogen, therefore, does not seem to be necessary for survival of autografts in the ewe. The technique for skin grafting used in this study differed from that reported by Beer \& Billingham (1970) in that free tail-skin grafts in their study on rats were not anchored to the uterine wall and the grafts were completely inside the uteri. Even though the grafts in the ewes were anchored with wound clips, the clips did not seem to be 


\section{PLATE 1}



FIG. 1. Intrauterine skin autograft (left) and allograft (right) 21 days after transplantation into an ovariectomized ewe. 'The autograft is healthy with a new growth of wool. The allograft is absent. Two wound clips are visible where the ends of the graft were exposed outside the uterus. Note the ends of the graft on the outside of the uterus on the section on the left.

Fig. 2. Cross-section of an intrauterine autograft at 21 days after grafting. Viability of the graft was indicated by the presence of dermal papillae, numerous hair follicles and glandular structures. $\times 60$. 
responsible for survival of autografts because they did not inhibit the rejection of the allografts.

Intrauterine allografts in rats survived when they were inserted during the preimplantation stage of pregnancy (Watnick \& Russo, 1968), when progesterone and oestrogen were given daily (Watnick \& Russo, 1968) and when oestrogen was given weekly in massive doses (Zipper et al., 1966). Allografts transplanted superficially in the endometrium of pregnant and pseudopregnant rabbits survived for at least 15 days after transplantation, whereas allografts transplanted deeply into the endometrium succumbed in a shorter time (McLean \& Scothorne, 1968). The levels of hormones used in the ewes of this study have not been shown to allow embryonal implantation, but these levels did maintain pregnancy in ovariectomized ewes from Days 28 to 56 (Ellicott, 1971). Kirby, Billington \& James (1966) suggested that the decidual layer between the graft and endometrium of the mouse interferes with the development of a host immunological response. Even though the hormone levels may have been adequate for allograft survival in the ewe, the lack of decidualization may have allowed the development of a host response. Parathyroid gland grafts were rejected within 20 days when grafted into non-decidualized uteri of pseudopregnant and non-pseudopregnant rats (Poppa et al., 1964).

Watnick \& Russo (1968) also found that the portions of allografts protruding from the uterus into the peritoneal cavity remained intact even though the tissue inside the uterus was rejected. They suggested that the tissue outside the uterus may not have been exposed to sufficient numbers of lymphocytes for rejection.

It is difficult at this time to explain why intrauterine grafts behave differently in sheep and rats. Some possible explanations might involve differences in the mechanisms of implantation, or differences in the feto-maternal placental relationships. Further research is needed beyond this preliminary report to elucidate this problem.

\section{REFERENCES}

Beer, A. E. \& Billingham, R. E. (1970) Implantation, transplantation and epithelial-mesenchymal relationships in the rat uterus. F. exp. Med. 132, 721 .

Ellicotr, A. R. (1971) Contributions of the ovary to maintenance of pregnancy in the gilt and ewe. Ph.D. thesis, University of Illinois.

Kirby, D. R. S., Billington, W. D. \& James, D. A. (1966) Transplantation of eggs to the kidney and uterus of immunized mice. Transplantation, 4, 713.

MaLean, J. M. \& Scothorne, R. J. (1968) Observations on the fate of autografts and homografts of the skin in the rabbit's uterus. F. Anat. 103, 402.

Poppa, G., Simmons, R. L., David, D. S. \& Russell, P. S. (1964) The uterus as a recipient site for parathyroid homotransplantation. Transplantation, 2, 496.

Watnick, A. S. \& Russo, R. A. (1968) Survival of skin homografts in uteri of pregnant and progesterone-estrogen treated rats. Proc. Soc. exp. Biol. Med. 128, 1.

Zipper, J., Ferrando, G., Saez, G. \& Tchernitchin, A. (1966) Intrauterine grafting in rats of autologous and homologous adult rat skin. Am. F. Obstet. Gynec. 94, 1056. 